\title{
Functional characterisation of Arabidopsis SPL7 conserved protein domains suggests novel regulatory mechanisms in the $\mathrm{Cu}$ deficiency response
}

Antoni Garcia-Molina ${ }^{1,2}$, Shuping Xing ${ }^{1,3}$ and Peter Huijser ${ }^{1 *}$

\begin{abstract}
Background: The Arabidopsis SQUAMOSA PROMOTER-BINDING PROTEIN-LIKE (SPL) transcription factor SPL7 reprograms cellular gene expression to adapt plant growth and cellular metabolism to copper (Cu) limited culture conditions. Plant cells require Cu to maintain essential processes, such as photosynthesis, scavenging reactive oxygen species, cell wall lignification and hormone sensing. More specifically, SPL7 activity promotes a high-affinity Cu-uptake system and optimizes Cu (re-)distribution to essential Cu-proteins by means of specific miRNAs targeting mRNA transcripts for those dispensable. However, the functional mechanism underlying SPL7 activation is still to be elucidated. As SPL7 transcript levels are largely non-responsive to Cu availability, post-translational modification seems an obvious possibility. Previously, it was reported that the SPL7 SBP domain does not bind to DNA in vitro in the presence of $\mathrm{Cu}$ ions and that SPL7 interacts with a kin17 domain protein to raise SPL7-target gene expression upon Cu deprivation. Here we report how additional conserved SPL7 protein domains may contribute to the Cu deficiency response in Arabidopsis.
\end{abstract}

Results: Cytological and biochemical approaches confirmed an operative transmembrane domain (TMD) and uncovered a dual localisation of SPL7 between the nucleus and an endomembrane system, most likely the endoplasmic reticulum (ER). This new perspective unveiled a possible link between Cu deficit and ER stress, a metabolic dysfunction found capable of inducing SPL7 targets in an SPL7-dependent manner. Moreover, in vivo protein-protein interaction assays revealed that SPL7 is able to homodimerize, probably mediated by the IRPGC domain. These observations, in combination with the constitutive activation of SPL7 targets, when ectopically expressing the N-terminal part of SPL7 including the SBP domain, shed some light on the mechanisms governing SPL7 function.

Conclusions: Here, we propose a revised model of SPL7 activation and regulation. According to our results, SPL7 would be initially located to endomembranes and activated during ER stress as a result of Cu deficiency. Furthermore, we added the SPL7 dimerization in the presence of Cu ions as an additional regulatory mechanism to modulate the Cu deficiency response.

\footnotetext{
* Correspondence: huijser@mpipz.mpg.de

${ }^{1}$ Department of Comparative Development and Genetics, Max Planck

Institute for Plant Breeding Research, Cologne 50829, Germany

Full list of author information is available at the end of the article
} 


\section{Background}

SQUAMOSA PROMOTER BINDING PROTEINS (SBP) constitute a transcription factor (TF) family exclusively found in green plants. Arabidopsis thaliana (hereinafter Arabidopsis) homologs have been related to developmental and adaptive programmes, such as plastochron determination [1], leaf morphogenesis [2], vegetative phase transition [3], flowering [4], anther and gynoecium development [5-7] or innate immunity [8] and copper deficiency response $[9,10]$.

Despite evolutionary divergence between the different family members, the tertiary structure of all SBP proteins encompasses the founding SBP-domain. It consists of a 76 amino acid signature including a functional bipartite nuclear localisation signal (NLS) and a series of 8 conserved cysteine and histidine residues organized in two unconventional zinc fingers (ZF1 and ZF2) [11-13]. Structural and functional studies suggested that ZF1 would maintain the SBP folding, while ZF2 would confer selectivity for the DNA sequence to bind $[14,15]$. Therefore, the SBP domain facilitates nuclear translocation and confers the capability to bind DNA-motifs harbouring a GTAC core sequence $[11,16,17]$.

The SBP genes appear in moderately sized-families. The Arabidopsis genome encodes 16 different SBP-Like (SPL) proteins grouped in 2 classes according to size, sequence similarity and structure and expression patterns of the respective genes. Based on these criteria, the denoted large SPLS (SPL1/7/12/14/16) conform a class representing the most complex and constitutively expressed genes. The other class is constituted by the small SPLS, whose expression is refined by the well-conserved and related microRNAs $m i R 156 / 7$, with SPL8 as a notable exception $[18,19]$.

In recent years, the Chlamydomonas reinhardtii Copper response regulator $\mathrm{Crr} 1$ and its closest Arabidopsis homolog SPL7 attracted attention because of their deeply conserved function as central orchestrators of $\mathrm{Cu}$ homeostasis $[9,10,17]$. $\mathrm{Cu}$ is an essential micronutrient for virtually all eukaryotes since its redox properties are optimal for essential catalytic functions in protein complexes. Indeed, plant cells rely on $\mathrm{Cu}$-proteins to deal with oxidative stress, energy production, lignification, or pollen tube guidance $[20,21]$. Furthermore, $\mathrm{Cu}$ has also been reported to play a structural role in the ethylene and salicylic acid receptors, as well as in the molybdenum cofactor [22-24]. However, an excess of free $\mathrm{Cu}$ ions will damage cellular components, e.g. lipids, proteins or nucleic acids, due to the generation of reactive oxygen species (ROS) [25]. To cope with this dual nature of $\mathrm{Cu}$, cells possess a fine-tuned homeostatic network aimed at maintaining $\mathrm{Cu}$ levels within a proper range. Although the general features of this network are conserved among all eukaryotes, main evolutionary divergences concern the regulatory mechanisms. During $\mathrm{Cu}$ starvation in Arabidopsis, SPL7 directly binds to GTAC motif-containing $\mathrm{Cu}$ response elements (CuRE) located in the promoter regions of $\mathrm{Cu}$ responsive genes [10,11]. In a first response, a $\mathrm{Cu}$-uptake system based on the $\mathrm{Cu}$-metalloreductases $\mathrm{FRO} 4 / 5$ and the plasma membranerelated $\mathrm{Cu}$ transport proteins COPT1/2/6 is promoted $[9,10]$. Secondly, SPL7 reprograms cellular gene expression for a more efficient $\mathrm{Cu}$ usage and (re-)distribution within the plant, thereby prioritizing delivery to essential enzymes. In this way, levels of particular microRNAs, denoted $\mathrm{Cu}$-miRNAs and including miR398 and miR408, are raised to translationally repress production of non-essential $\mathrm{Cu}$-requiring proteins, such as the cytosolic $\mathrm{Cu} / \mathrm{Zn}$ superoxide dismutase (CSD1), chloroplastic CSD2, plantacyanin or the laccases. Suppression of CSD2 and the promotion of FSD1 represent a coordinated substitution of the chloroplastic superoxide dismutases that facilitates a preferential delivery of $\mathrm{Cu}$ to plastocyanin (PC) $[9,10,20]$.

However, the mechanism underlying SPL7 activation is not fully understood, especially with regard of $\mathrm{Cu}$ sensing and protein regulation. SPL7 is a constitutively expressed gene detected in all plant tissues regardless of $\mathrm{Cu}$ availability. Consequently, a post-translational regulation for this TF has been proposed $[9,10,20]$. Within this context, we recently reported the physical interaction between SPL7 and a kin17-domain encoding protein (KIN17) to stimulate SPL7 targets during $\mathrm{Cu}$ starvation [26]. Moreover, the in vitro SBP-DNA binding could be prevented by $\mathrm{Cu}$ ions probably replacing complexed $\mathrm{Zn}$ ions and thereby changing the conformation of SPL7-like proteins $[14,17]$. Here, we present a functional characterisation of conserved domains in the SPL7 protein as to come to a better understanding of how its activity may be regulated in response to cellular $\mathrm{Cu}$ status in Arabidopsis. Our subcellular and biochemical approaches revealed that the presence of a TMD recruits SPL7 to the microsomal fraction, likely at the ER membrane and suggests a proteolytic cleavage prior to its nuclear translocation. Interestingly, our data indicate that $\mathrm{Cu}$ deficiency implicates ER stress and could constitute a driving force to activate SPL7. Moreover, a SPL7 dimerization domain could act in a mechanism to prevent the protein from entering the nucleus.

\section{Results}

A conserved transmembrane domain is sufficient to anchor SPL7-like proteins to the plasma membrane

In order to identify conserved protein signatures possibly participating in SPL7 function, we carried out a comprehensive multiple alignment among SPL7 and orthologs from different species including di- and monocots, a gymnosperm, a bryophyte and green algae. Initially, we paid attention to a 20 amino acid hydrophobic region 
located in the carboxy-terminal region, and found it to be conserved in all higher plant SPL7 homologs (Additional file 1: Figure S1a). The TMHMM prediction service (www.cbs.dtu.dk/services/TMHMM/ [27]) retrieved this region as a putative TMD. Therefore, to investigate whether this domain is capable of tethering SPL7 to cellular membranes, we fused the TMD C-terminal to the green fluorescent protein (GFP) (GFP::TMD; Figure 1a) and transiently expressed it in tobacco leaves. In order to discriminate the plasma membrane, samples were incubated with the lipophilic styryl dye FM4-64 under cold conditions. As shown in Figure 1b, confocal

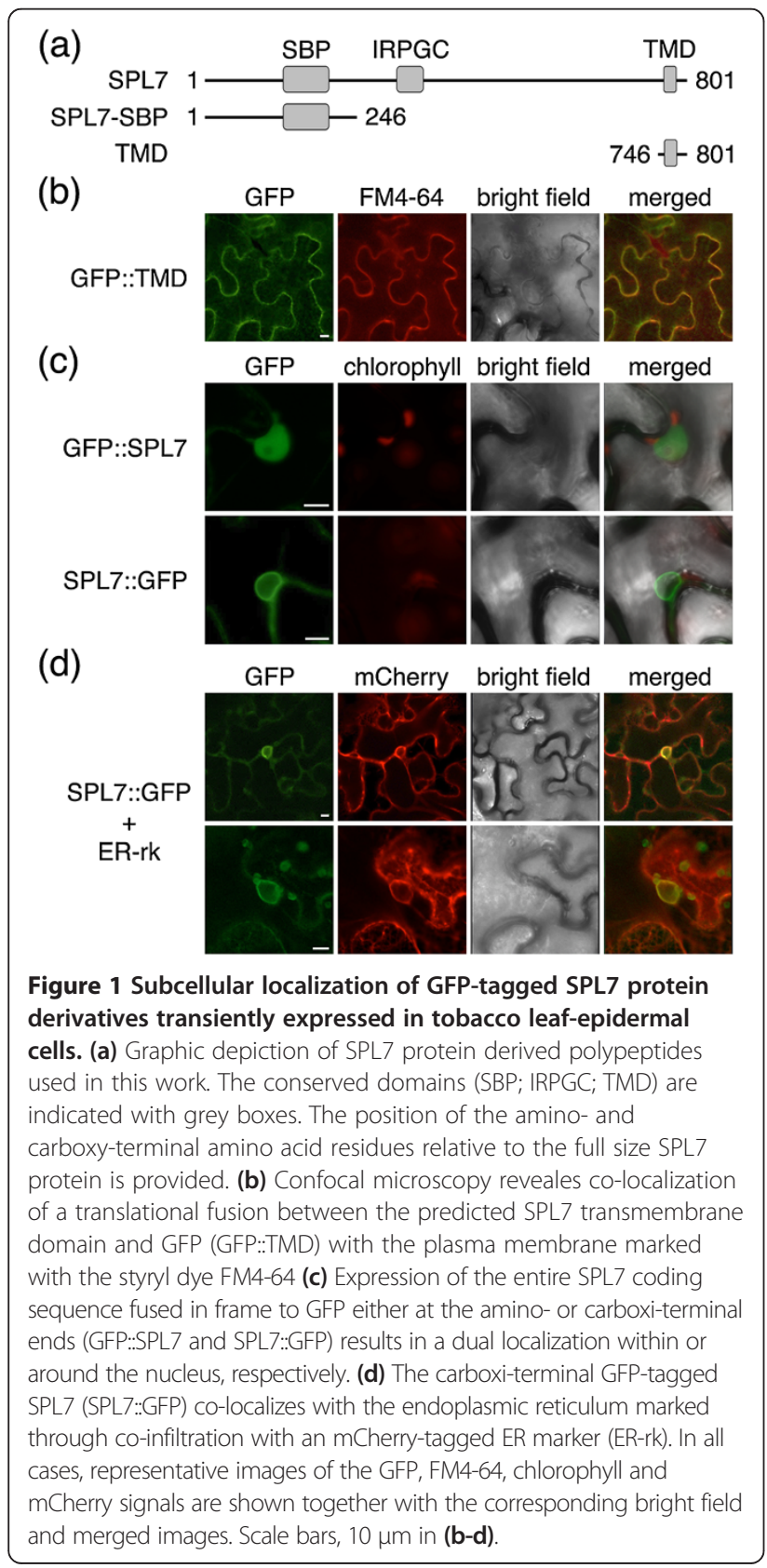

imaging revealed a GFP signal outlining the transformed cells and perfectly overlapping with the FM4-64 signal.

To further confirm our data, we also performed a biochemical fractionation using total extracts from transfected tobacco leaves. Enriched microsomal (M), cytosolic (C) and nuclear $(\mathrm{N})$ fractions were analysed by Western blot using antibodies against GFP and selected organelle markers. In this case, the GFP::TMD clearly associated with the microsomal fraction (Figure 2a). Altogether these observations point to the predicted TMD domain as able and sufficient to anchor proteins to the plasma membrane.

SPL7 exhibits a dual subcellular localisation and likely requires proteolytic cleavage to become translocated to the nucleus

The above-stated results concerning the presence of a TMD seem to oppose the function of a conserved bipartite

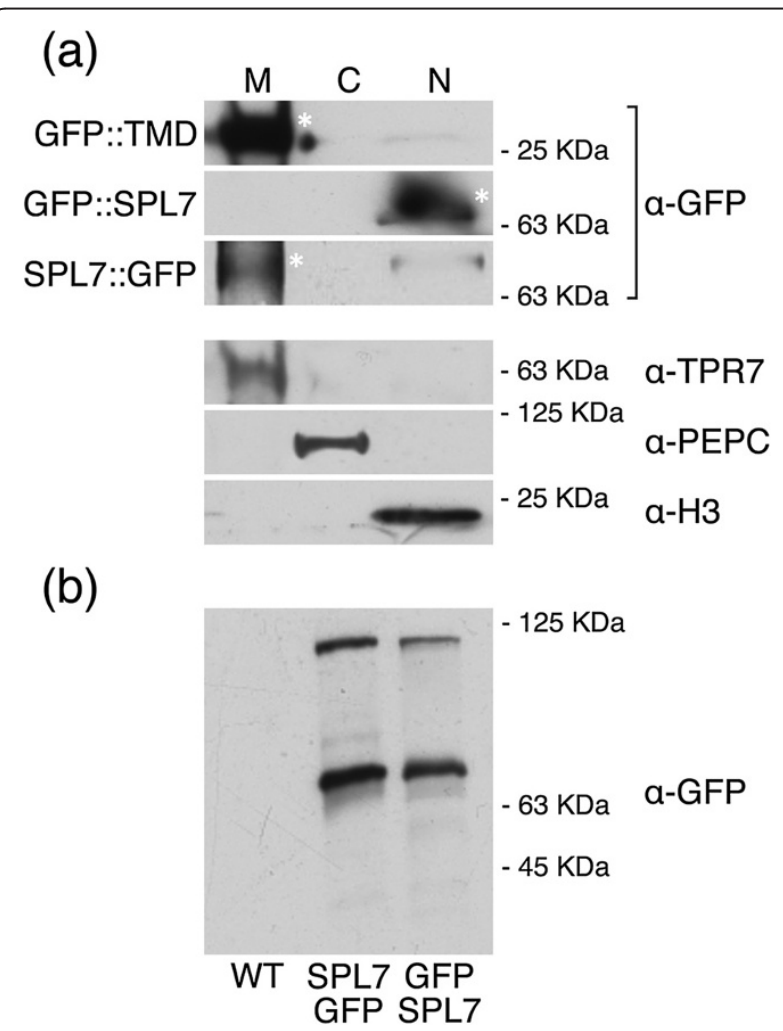

Figure 2 Biochemical analysis of SPL7 subcellular localization and processing. (a) Total protein extracts from tobacco leaves transiently expressing different GFP-tagged SPL7 versions were subjected to biochemical fractionation, as described in Experimental Procedures and analysed by Western blotting with antibodies against GFP ( $a-G F P)$. Antibodies against the organelle markers TPR7 ( $a-$ TPR7), PEPC ( $a-P E P C)$ and histone $\mathrm{H} 3(\mathrm{a}-\mathrm{H} 3)$ were used to validate the fractionation. $\mathrm{M}$, microsomes; C, cytosol; N, nucleus. Main bands are highlighted with an asterisk. (b) Proteolytic processing of transiently expressed GFP:.SPL7 and SPL7:GFP by Western blotting. WT, protein extract of non-transformed tobacco leaves. Sizes of molecular-weight markers run in the same gels are shown alongside the blots in (a-b) according to manufacturer's indications for 10\% SDS-PAGE gels. 
NLS within the SBP domain and the rather constitutive nuclear localization reported in our previous observations, as well as for several other SBP-domain proteins $[11,14,26]$. Therefore, we addressed the question whether SPL7 could display a dual subcellular distribution. For this purpose, we generated CaMV 35S promoter-driven transgenes consisting of the entire SPL7 coding region and fused in frame either $5^{\prime}$ or $3^{\prime}$ to GFP to allow the constitutive expression of either N-terminal or C-terminal tagged SPL7 protein (GFP::SPL7 and SPL7::GFP; Figure 1a). Since we failed to reliably detect GFP fluorescent signals in Arabidopsis plants stably transformed with these constructs, we decided to use agro-infiltration of tobacco leaves as a heterologous system to assess the subcellular localization of the encoded protein products. Strikingly, while GFP::SPL7 distributed homogeneously within the nucleoplasma excluding the nucleolus, the C-terminal tagged version located around the nucleus and to filamentous structures in cytoplasmic strands (Figure 1b, 1c and Additional file 2: Figure S2). As the latter pattern suggested possible association with the ER, we co-infiltrated the SPL7:: GFP-encoding construct with an ER marker fused to the mCherry fluorescent protein (ER-rk [28]). This revealed a high degree of co-localization of both fluorescent signals, most intensely around the nucleus (Figure 1d). Moreover, we also subjected total extracts from 35S::GFP::SPL7 and 35S::SPL7::GFP transformed leaves to a biochemical fractionation, as described above. Indeed, GFP::SPL7 protein was detected in the nuclear enriched fraction, whereas SPL7::GFP primarily associated with the microsomal fraction (Figure 2a), thereby corroborating the microscopic observations. Consequently, these data strongly suggest SPL7 to distribute between the nucleus and the endomembrane system.

Interestingly, although estimating that GFP would contribute $\sim 23 \mathrm{KDa}$ and SPL7 $\sim 90 \mathrm{KDa}$, the observed apparent molecular weight of both GFP-tagged SPL7 versions seemed more consistent with $\sim 63 \mathrm{KDa}$ (Figure 2a). Since membrane-anchored proteins must be somehow released prior to their translocation to the nucleus and exert their function, we investigated if these observed bands could correspond to cleaved SPL7 products. To this end, total protein extracts from transformed tobacco leaves expressing either GFP::SPL7 or SPL7::GFP were also analysed by Western blot. A pattern including two specific bands was obtained regardless of the position of the tag (Figure 2b). We considered that the upper band $(\sim 125 \mathrm{KDa})$ could correspond to the full-sized SPL7 while the presence of the second lower band $(\sim 63 \mathrm{KDa})$ in both cases might be explained if SPL7 would have been cleaved in the middle (Figure $2 \mathrm{a}$ ). This processing would thus render a derived polypeptide fitting the observed size $(\sim 45 \mathrm{KDa}$ from half of SPL7 $+\sim 23 \mathrm{KDa}$ from GFP; Figure 2a,b).
These results are consistent with an arranged pattern where the N-terminal half of SPL7 translocates to the nucleus following proteolytic cleavage, whereas the C-terminal half would remain attached to some endomembrane, such as the ER.

\section{Cu deficiency generates endoplasmic reticulum stress, a metabolic perturbation that promotes SPL7 target activity} Because SPL7 transcript levels remain relatively constant irrespective of $\mathrm{Cu}$ availability, post-translational mechanisms have been proposed to regulate this TF $[9,10,20,26]$. Assuming that SPL7 could be initially attached to the ER membrane, we wondered whether perturbations affecting the functionality of this organelle would trigger SPL7 processing and activation. In this context, it is well known that adverse environmental conditions result in miss-folding of ER-resident proteins [29,30]. To counteract this so-called ER stress, a defined unfolded protein response (UPR) is generated through the activation of genes coding for folding-assisting proteins $[29,30]$. Curiously, genes categorized as UPR markers appeared relatively down-regulated in a transcriptomic assay in shoots from plants hydroponically cultured on $\mathrm{Cu}$ sufficient media [9]. Thus, we decided to investigate whether varying $\mathrm{Cu}$ supply may influence ER stress. Thereto, transcript levels of reported UPR markers were determined in seedlings grown on $1 / 2$ MS media supplemented with either the $\mathrm{Cu}$-specific chelator BCS $50 \mu \mathrm{M}$ (Cu deficiency), $\mathrm{CuSO}_{4}$ $1 \mu \mathrm{M}$ ( $\mathrm{Cu}$ sufficiency) or $10 \mu \mathrm{M}$ (Cu excess). Interestingly, our selected markers, including the TF bZIP60 (At1g42990), the disulfide isomerase-like protein (PDIL; At1g21750), the luminal binding proteins BiP1,2 (At5g28540/At5g42020) and calreticulin (CRT1; At1g56340) were all slightly induced (ca. 1.4-fold) following $\mathrm{Cu}$ deficient conditions (Figure 3). Our results thus uncovered that $\mathrm{Cu}$ deficiency to some degree seems to result in ER stress.

To further investigate the likely connection between ER stress and SPL7 activation, we monitored the behaviour of SPL7 target genes in seedlings treated with UPR-inducing drugs. Thereto, 5-day-old wild type seedlings grown on low but $\mathrm{Cu}$ sufficient medium ( $1 / 2 \mathrm{MS}$ supplemented with $\mathrm{CuSO}_{4} 0.5 \mu \mathrm{M}$ [31]) were incubated for $3 \mathrm{~h}$ on liquid $1 / 2$ MS with tunicamycin [32], an inhibitor of N-linked protein glycosylation, or dithiothreitol (DTT), disrupting disulphide bond formation. The presence of ER stress in our experimental conditions was confirmed by raised BiP1,2 and CRT1 transcript levels in comparison to controls (Figure 4). Moreover, the transcript abundance of the analysed SPL7 targets was generally increased, with DTT producing a more prominent effect (Figure 4). Indeed, seedlings exposed to DTT raised transcript levels of FSD1, COPT1 and MIR398C ca. 1.4-fold in comparison to untreated controls, while COPT2 showed the strongest induction (2.8-fold) (Figure 4). In addition, since this 

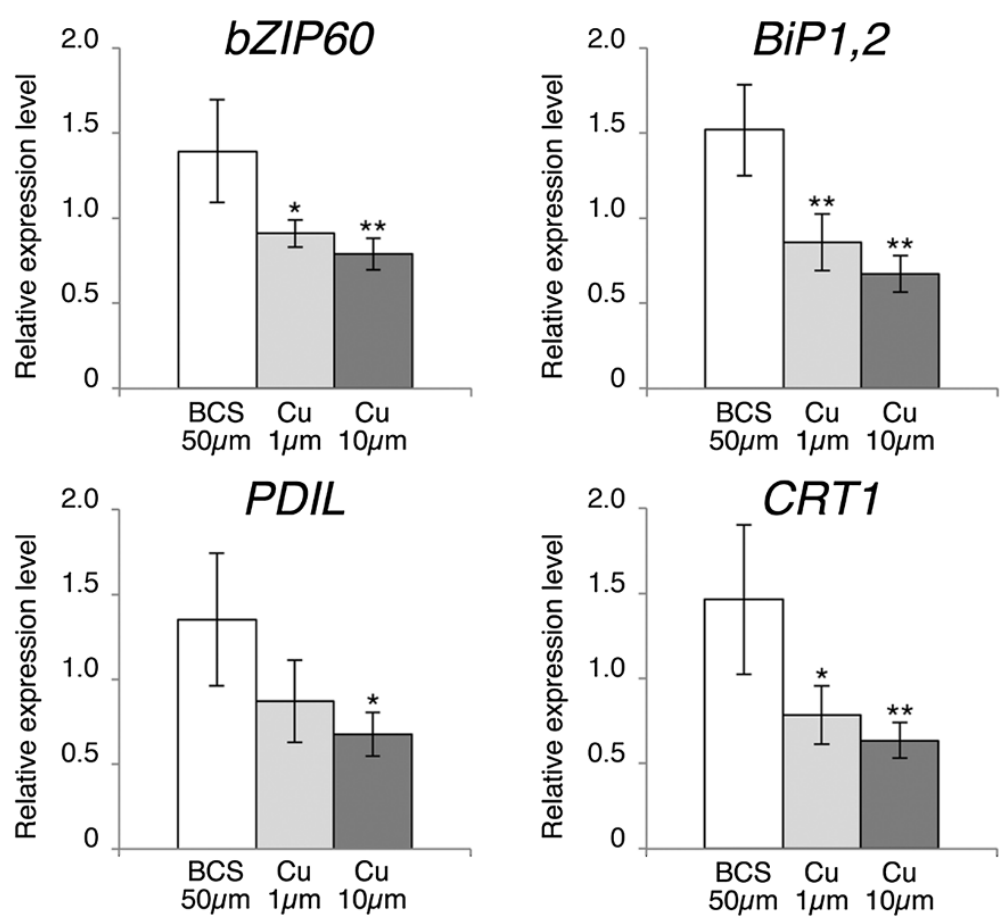

Figure $3 \mathrm{Cu}$ deficiency induced ER-stress markers. The relative mRNA levels of indicated ER-stress markers were determined by qPCR on RNA from 7-day-old wild-type Arabidopsis seedlings grown on $1 / 2 \mathrm{MS}$ supplemented with BCS $50 \mu \mathrm{M}, \mathrm{CuSO}_{4} 1 \mu \mathrm{M}$ or $10 \mu \mathrm{M}$. Error bars indicate standard deviation ( $n \geq 3$ independent biological samples), asterisks indicates statistically significant difference to Cu deficiency conditions in Student's $t$-test $\left({ }^{*} p<0.05 ;{ }^{* *} p<0.01\right)$.

response could not be observed in the spl7-2 mutant line, we concluded that the stimulation of the $\mathrm{Cu}$-response during ER stress is SPL7-dependent. Altogether, our results suggest that $\mathrm{Cu}$ deficiency induces ER stress, which could be used as a signal to promote the activation of SPL7.

\section{SPL7 is able to homodimerize in vivo}

Protein-protein interactions could also constitute a post-translational mechanism to refine SPL7 function. Therefore, we conducted a yeast-two-hybrid ( $\mathrm{Y} 2 \mathrm{H})$ screening aimed at identifying putative SPL7-interacting proteins. Besides KIN17, on which we recently reported [26], 8 different preys corresponding to SPL7 itself were fished when using an SPL7 fragment as bait, strongly suggesting SPL7 homodimerization (Additional file 3: Figure S3). Interestingly, all preys encompassed an evolutionary wellconserved ca. 50 aa signature marked by the so-called IRPGC domain (Figure 1a, Additional file 1: Figure S1 and Additional file 3: Figure S3 [16,17]). To further confirm the SPL7-SPL7 interaction, the entire SPL7 coding sequence was amino-terminally fused to the Influenza hemagglutinin (HA) epitope tag (HA::SPL7) and co-expressed with GFP::SPL7 in tobacco leaves. Subsequent Western blot analysis uncovered that GFP::SPL7 co-immunoprecipitated with HA::SPL7 in a HA pull-down assay (Figure 5a).
Remarkably, because the co-immunoprecipitated peptides corresponded in size to the putative SPL7-processed version (Figure 5a), we concluded that the dimerization likely constitutes a post-cleavage event. Moreover, the SPL7 homodimerization was also ascertained by bimolecular fluorescence complementation (BiFC). For this purpose, in-phase translational fusions between the entire SPL7 coding sequence and the two split-yellow fluorescent protein (YFP) halves in amino-terminal position (nYFP::SPL7 and cYFP::SPL7) were generated and co-expressed in tobacco leaves. Whereas expression of the individual constructs with the complementary empty vector did not generate any specific YFP-derived fluorescence, concomitant expression resulted in a YFP signal mainly located at the nuclei in widefield epifluorescence microscopy (Figure 5b). However, confocal microscopy enabled a more accurate observation of the reconstituted YFP fluorescence signal and revealed a pattern mirroring the endomembrane system, as previously observed for SPL7::GFP, and largely excluded from the nucleus (Figures $1 \mathrm{c}$ and $5 \mathrm{c}$ ). On the contrary, a YFP signal could not be reconstituted when using carboxy-terminal fusions (data not shown). Taken these data together, we conclude that SPL7 dimerization takes place outside the nucleus, probably at or in the vicinity of the ER after being processed. We may envisage that this dimerization constitutes a regulatory mechanism to restrict 

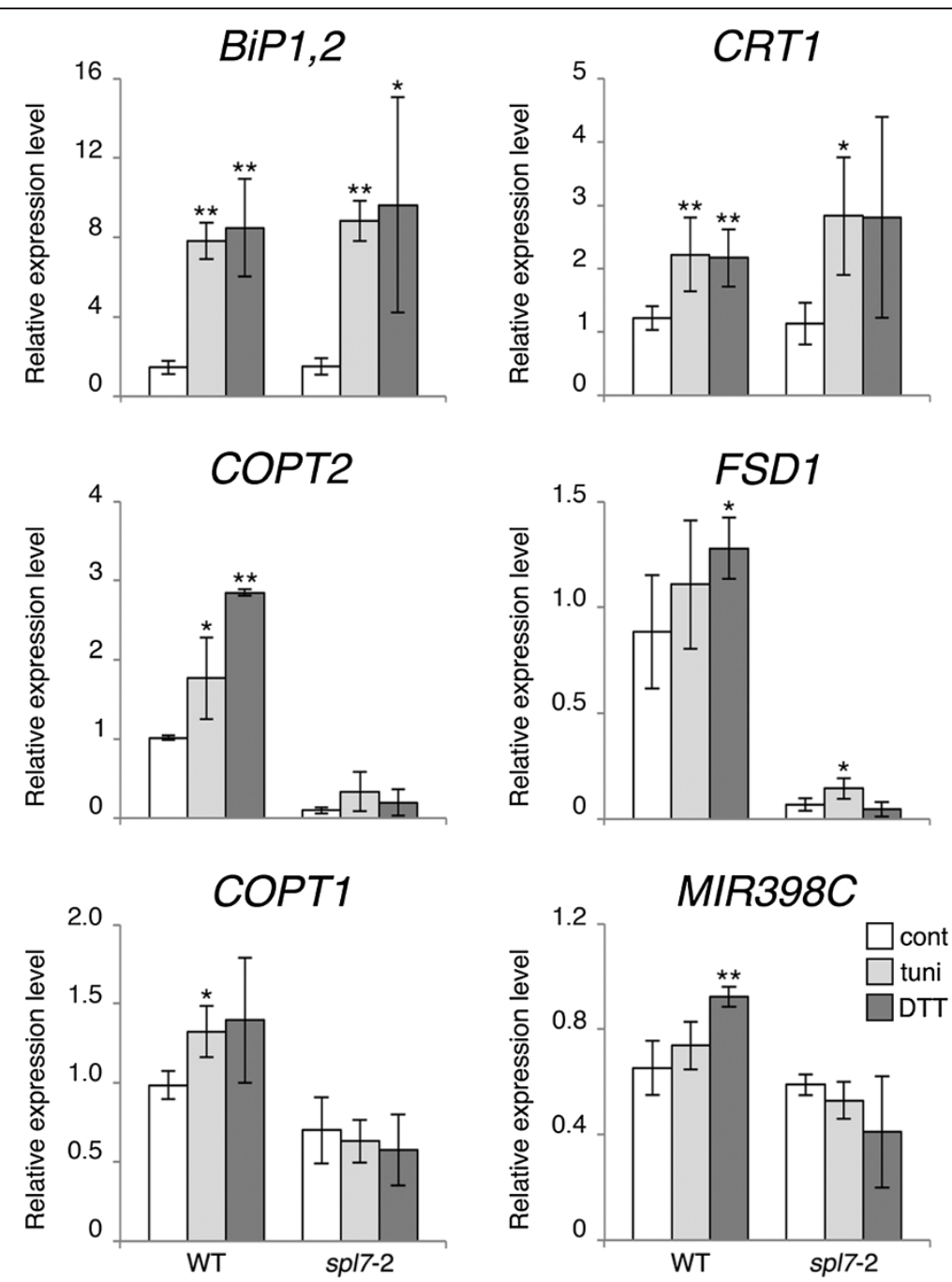

Figure 4 Induction of SPL7 targets following ER stress. Arabidopsis wild-type (WT) and spl7-2 mutant seedlings grown on 1/2 MS supplemented with

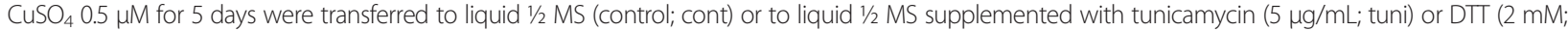
DTT) for 3 hours. Total RNA was isolated and relative transcript levels of selected SPL7 targets monitored by qPCR. Error bars indicate standard deviation ( $n \geq 3$ independent biological samples), asterisks statistically significant difference to control conditions in Student's t-test $\left({ }^{*} p<0.05 ;{ }^{* *} p<0.01\right.$ ).

SPL7 from entering the nucleus, i.e. as a negative feedback mechanism.

\section{Arabidopsis transgenic lines expressing the SPL7-SBP domain exhibit constitutive activation of SPL7 targets} In addition to the above-mentioned post-translational processing and protein-protein interactions, i.e. proteolytic cleavage and dimerization, SPL7 function may also be altered following conformational changes. Indeed, $\mathrm{Cu}$ ions have been reported to preclude both Chlamydomonas Crr1-SBP and SPL7-SBP DNA-binding capability in vitro [14]. Consequently, the replacement of $\mathrm{Zn}$ ions by $\mathrm{Cu}$ at the ZFs results in a conformational change that could constitute an additional regulatory mechanism to inactivate SPL7. To further validate this postulate in vivo, stably transformed lines constitutively expressing a GFP-tagged
SPL7 protein truncated immediately behind the SBP domain were generated in the spl7-2 background (GFP::SBP; Figure 1a). Importantly, GFP::SBP/spl7-2 lines were not only able to complement the spl7 mutant phenotypes under $\mathrm{Cu}$ limitation with respect to root growth, size or silique production (Additional file 4: Figure S4), but a GFP signal also became microscopically detectable in planta (Figure 6). GFP::SBP fluorescent signal could be detected at high levels within nuclei of both roots and shoots of 5-day-old seedlings grown on media differing in $\mathrm{Cu}$ availability (Figure 6). These observations indicate that $\mathrm{Cu}$ availability does not markedly affect stability of the SPL7-SBP domain.

Then, to learn if $\mathrm{Cu}$ actually impedes functionality of the SBP domain, transcript levels of selected SPL7-targets were monitored by qPCR in 7-day-old wild-type and 


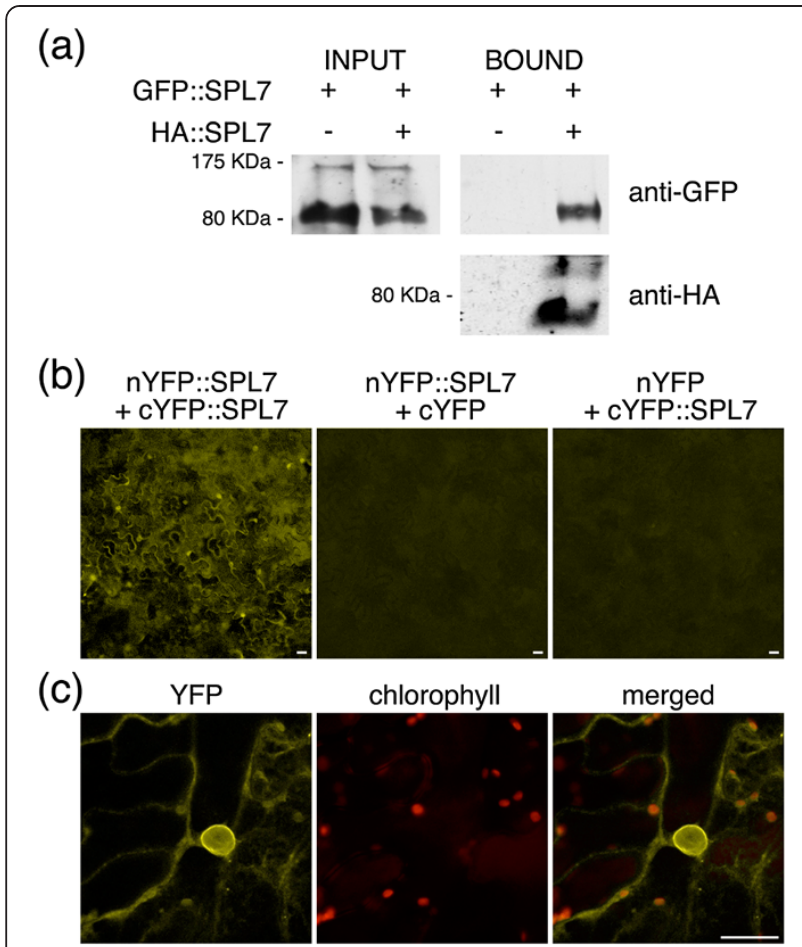

Figure 5 SPL7 homodimerizes in vivo. (a) For a pull-down assay by means of an antibody against HA (BOUND), total protein was extracted from tobacco leaves transiently expressing full-size SPL7 tagged either with GFP or HA epitopes (GFP.:SPL7 and HA::SPL7; INPUT). Input and bound fractions were assayed by Western blot using an anti-GFP antibody to assess GFP::SPL7 co-immunoprecipitation. Membranes were reprobed with an anti-HA-HRP (anti-HA) antibody to check for HA:SPL7 pull-down. Sizes of molecular-weight markers run on the same gels are indicated at the left according to manufacturer's indications for precasted gels. Note that the apparant molecular weights may differ in comparison to those shown in Figure 2 due to the use of a different separation matrix for electrophoresis. (b) For bimolecular fluorescent complementation (BiFC) analysis the split-YFP tags were $\mathrm{N}$-terminal fused to the full-size SPL7 protein (nYFP::SPL7, CYFP::SPL7) and co-expressed in tobacco leaves. Restoration of the YFP fluorescence signal could be observed with widefield epifluorescence microscopy using a YFP band-pass filter. Co-expression of the individual constructs with their complementary empty vectors (middle and right panels) did not result in reconstitution of YFP fluorescence. (c) A representative confocal microscopic image of the reconstituted YFP fluorescence illustrating its predominant extranuclear localization is shown together with chlorophyll autofluorescence and merged images. Scale bars, $25 \mu \mathrm{m}$.

GFP::SBP/spl7-2 seedlings grown on a gradient of $\mathrm{Cu}$ concentrations. To this end, the standard $1 / 2 \mathrm{MS}(\mathrm{Cu}$ deficiency) was supplemented with $\mathrm{CuSO}_{4}$ to achieve $\mathrm{Cu}$ sufficiency $(1 \mu \mathrm{M})$ or $\mathrm{Cu}$ excess $(5-50 \mu \mathrm{M})$. As shown in Figure 7, COPT2, pre-miR398c and $\mathrm{CCH}$ transcript levels in wild type already reached their minimum in the presence of $1 \mu \mathrm{M} \mathrm{Cu}$, i.e. a drastic reduction of ca. 20-fold, 10-fold and 4-fold, respectively, compared to $\mathrm{Cu}$ deficient conditions. In contrast, a similar comparison between the GFP::SBP/spl7-2 lines showed a

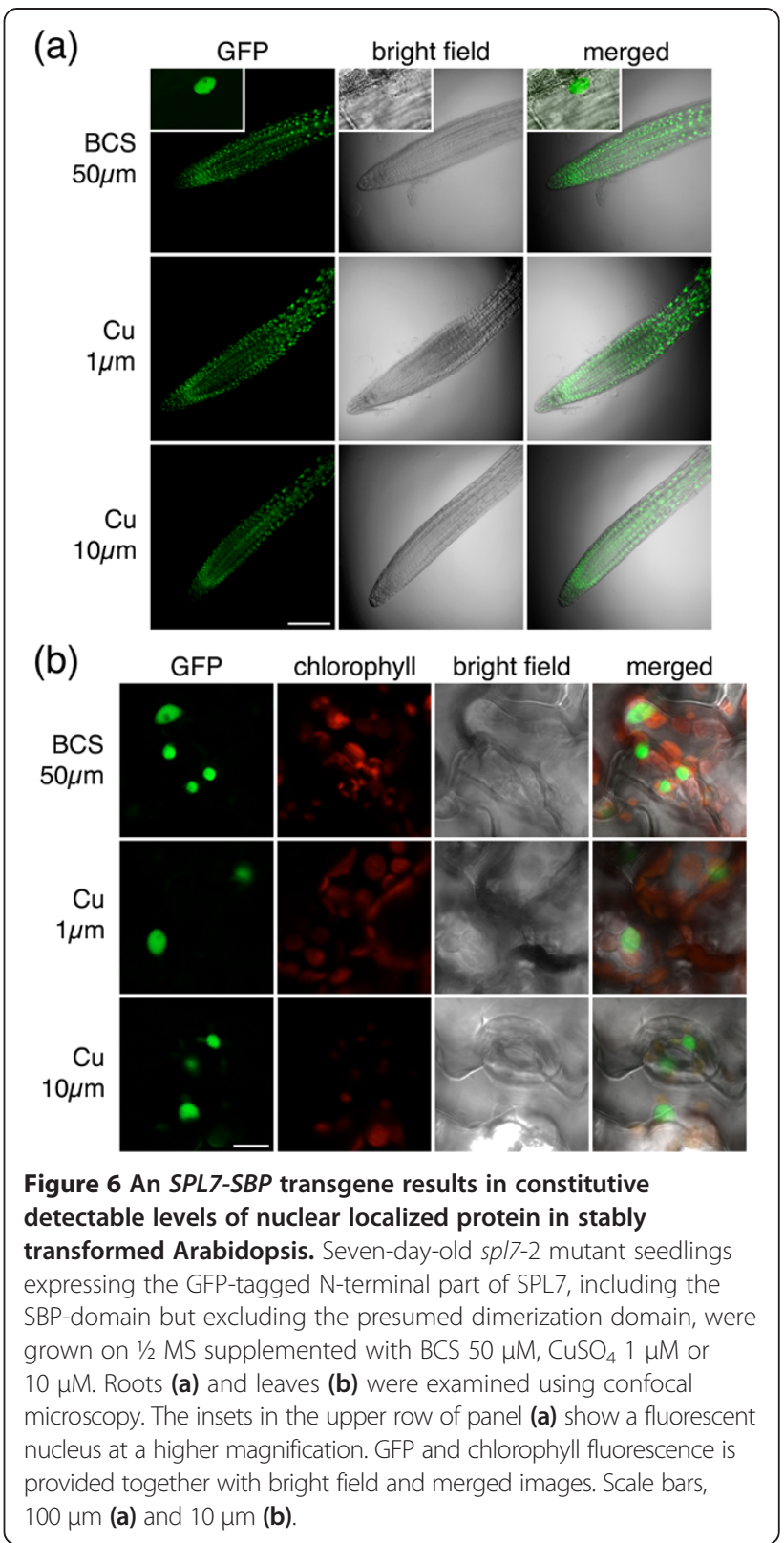

more moderate reduction of ca. 5-fold for $\mathrm{CCH}$ and less than 2-fold for COPT2 and MIR398C and remained significantly higher in comparison to wild type (Figure 7). Moreover, these elevated levels in the transgenic seedlings remained largely constant along the gradient, even under physiologically incompatible $\mathrm{Cu}$ conditions (Figure 7 ).

All together, our data indicate that neither the stability of the SBP domain nor its function is severely affected by $\mathrm{Cu}$ ions in planta. Based on these results, we suggest that protein domains outside the SBP-domain of SPL7 are likely to have a more profound effect on SPL7 activity in response to $\mathrm{Cu}$ availability. 


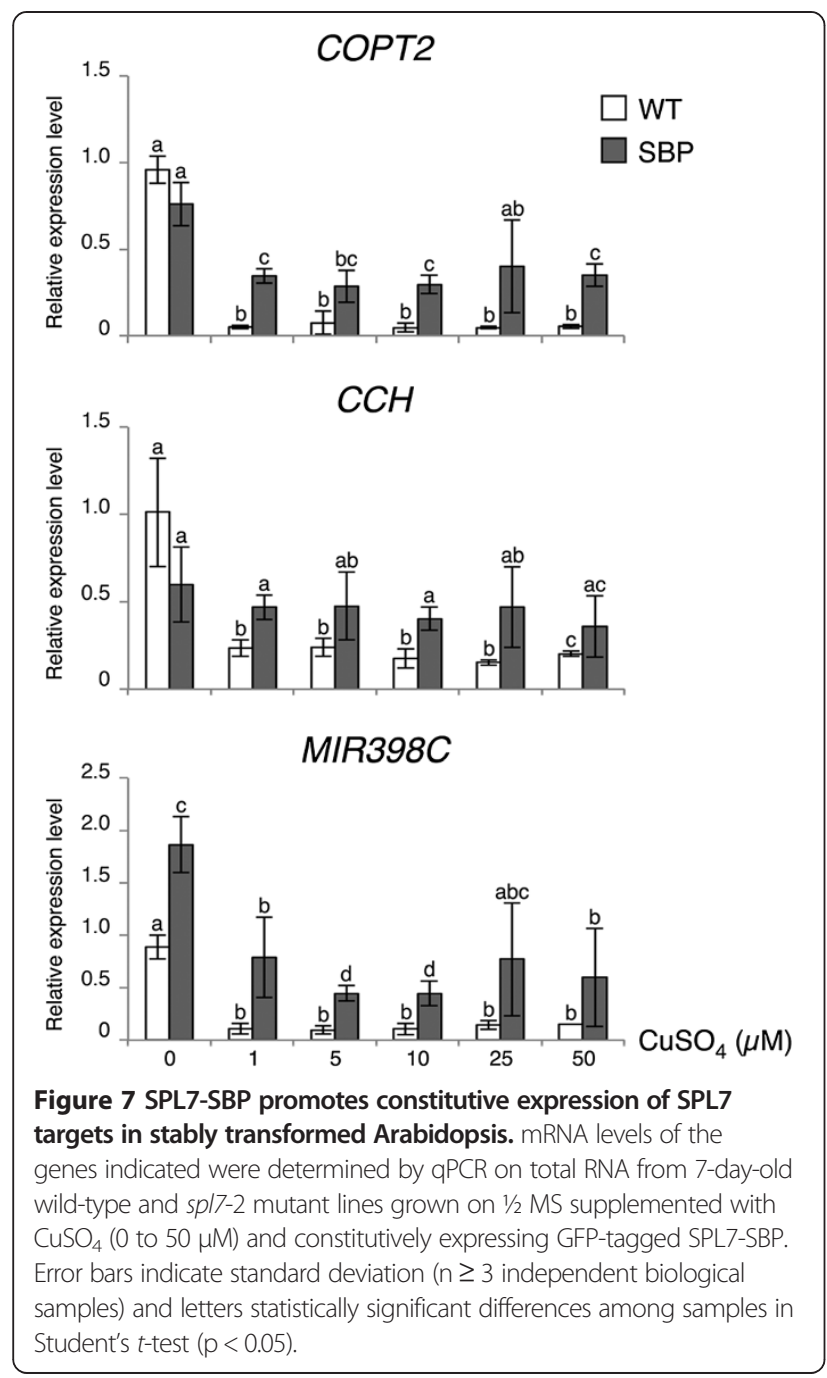

\section{Discussion}

Green plants, from single-celled algae to angiosperms, rely on an evolutionary well-conserved SBP-box TF to orchestrate their adaptive response to $\mathrm{Cu}$ deprived periods. As potential TFs, all SPL7-like proteins contain a functional bipartite NLS overlapping ZF2 within the SBP-domain $[11,12,26]$. However, our cellular and biochemical approaches confirmed the anchoring of SPL7 to the microsomal fraction, most likely to the ER-membrane, through a C-terminal TMD (Figure 8). Consequently, a not yet identified molecular mechanism must facilitate the observed dual localization of SPL7 in cells.

In this sense, ER-membrane tethered TFs (ER-MTTFs) might provide an illustrative example to infer the SPL7 mechanism since they exhibit a similar behaviour. This class of TFs display an initial latent form when attached to membranes and require some sort of processing to be released and eventually translocated to the nucleus [33]. ER-MTTFs nuclear-localised versions are generated as a result of two main strategies, namely mRNA processing

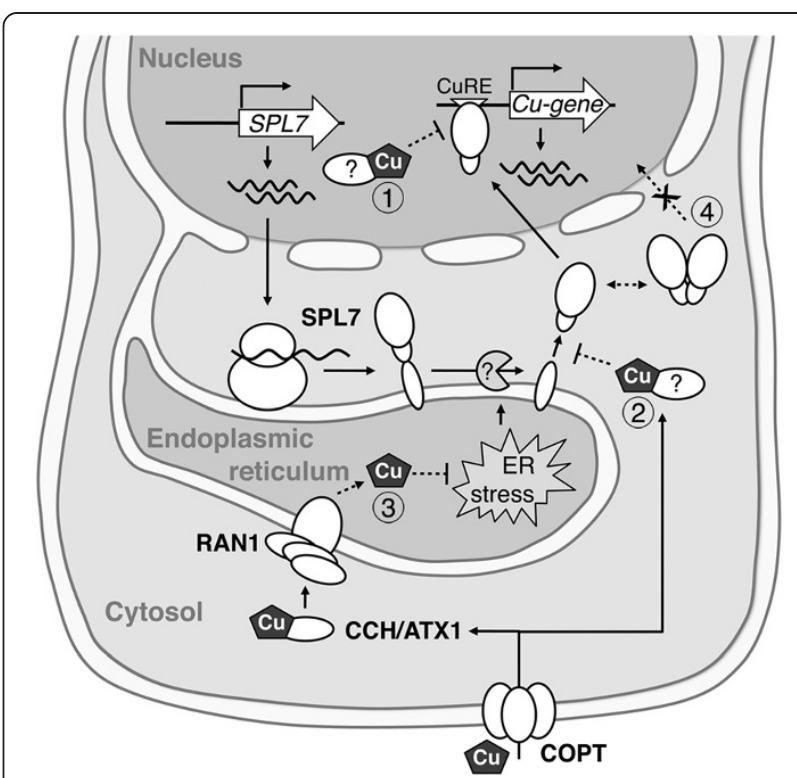

Figure 8 A working model for the regulation of SPL7 function.

Cu supply depends on extracellular input and mobilization from intracellular stores via selective Cu-transport proteins, COPT. Acquired $\mathrm{Cu}$ is complexed by a set of metallochaperones, like CCH and ATX1, and delivered to specific targets. As main orchestrator of the $\mathrm{Cu}$ starvation response, SPL7 may be among these targets in order to become or remain repressed in the presence of sufficient $\mathrm{Cu}$. This may be achieved through a direct interaction with delivered Cu resulting in an inability of SPL7 to bind to CURE motifs in the promoter regions of its targets genes (1). In addition or alternatively, proteolytic processing of ER membrane-tethered SPL7 may be repressed in the presence of $\mathrm{Cu}$ (2). As a consequence, activation of SPL7 in response to Cu-deficiency may thus result from a relief of these repression mechanisms. Furthermore, ER stress caused by a failure to fulfil the demand for $\mathrm{Cu}$ of proteins involved in the secretory pathway, may actively promote the release of the membrane-bound SPL7 (3). Finally, a precocious dimerization to modulate the $\mathrm{Cu}$ deficiency response as the amount of released SPL7 continues to raise may prevent SPL7 from entering the nucleus either due to NLS masking or exceeding the size exclusion limit of the nuclear pore (4).

and proteolytic cleavage. Although alternative mRNA splicing has been reported to produce a non-anchored version of the bZIP60 ER stress transducer [34,35], this mechanism would not be expected for SPL7 because its known or predicted splicing variants (AT5G18830.2 and -.3; TAIR10 genome release; www.arabidopsis.org) do not disrupt the TMD domain. More often, specific proteolytic activities, such as the regulated intramembrane proteolysis (RIP) and the rhomboid proteases, produce a cleavage at the vicinity of the TMD [36,37]. However, because the apparent molecular weights of both SPL7 nuclear and ER-attached fragments correspond approximately to half of that of the predicted full-size protein, a proteolytic cleavage in the middle is suggested as the strategy to release and activate SPL7 (Figure 8). Thus, regulated ubiquitin/ proteasome-dependent processing (RUP) and the so-called receptor-activated proteolysis (RAP) would be more 
conceivable for this case [38,39]. Nevertheless, we envisage a relative rapid-acting mechanism as the presence of the full-sized GFP::SPL7 was barely detectable in coimmunoprecipitation experiments and remained even undetectable following biochemical fractionation. Consequently, it would be particularly interesting to identify the responsible protease(s) and the cleavage site(s) in SPL7, as it will shed more light on the precise mechanism activating SPL7 and contribute to relate its function to additional biological responses.

The initial location of a likely dormant SPL7 at the ER provides a new perspective on the regulation of $\mathrm{Cu}$ homeostasis and requires a re-evaluation of the role of the so-called secretory pathway in $\mathrm{Cu}$ sensing. As represented in Figure $8, \mathrm{Cu}^{+}$imported by the selective $\mathrm{Cu}$-transport proteins CTR/COPT is bound and further distributed by $\mathrm{Cu}$-specific soluble factors or metallochaperones (for a comprehensive description see Burkhead and collaborators [20]). Among them, ATX1-like metallochaperones interact with the $\mathrm{P}_{\mathrm{B}}$-ATPase $\mathrm{Ccc} 2$ in Saccharomyces cereviseae, or RAN1/HMA7 in plants, in order to supply $\mathrm{Cu}$-proteins en route $[40,41]$. Whereas Ccc2 resides in the Golgi apparatus of yeast, the exact subcellular localization of Arabidopsis RAN1 has not yet been determined. However, since the ER-located ethylene receptors (ETRs) are largely dependent on $\mathrm{Cu}$ supply by RAN1, an ER location has been proposed [42-44]. Thus, unlike storage organelles as chloroplasts, mitochondria or vacuoles, the ER could act as a more reliable indicator of the steady-state $\mathrm{Cu}$ availability in the cell.

Notably, several studies have recently reported a central role of the ER in sensing/transducing cellular stresses $[37,45]$. In an attempt to identify ER perturbations that activate SPL7, our initial data suggest an impact in the ER protein-folding capacity during $\mathrm{Cu}$ starvation and how ER stress treatments slightly induced selected SPL7-targets in mild $\mathrm{Cu}$-sufficient seedlings. Whether the initial tethering of SPL7 to the ER-membrane could be a cellular strategy to sense $\mathrm{Cu}$ limitation through the stress it imposes to the ER needs to be further investigated. Within this context, it is also worth mentioning that the growth inhibitory effect of fumonisin B1 (FB1) was found attenuated in the fbr6 mutant, representing the SPL7-related SPL14 TF [2]. The apoptotic effect of the mycotoxin FB1 is related to a reduction in the cellular ceramide levels, a likely signal for ER-stress [46-48]. Given the conservation of the putative TMD among the large SPLs including SPL14, it would also be interesting to address if the strategy proposed for SPL7 could be extended to this class of TFs.

On the other hand, given that the SPL7 orthologs in single-celled algae lack a TMD, this domain could represent an innovation in the evolution of land plants [16]. The positive selection of the TMD may be related to the multicellular and more complex nature of land plants, where many different cell types likely differ in their requirements for $\mathrm{Cu}$ and their demand probably even changes with growth and development. Thus, anchoring SPL7-like proteins to membranes could play a role in finetuning their activities in a more cell-autonomous context. However, although further comparative studies between Crr1 and SPL7-like proteins are required to provide a more thorough answer, the existence of additional regulatory levels for these TFs in higher plants seems likely.

Based on our data, we also propose SPL7 homodimerization as another checkpoint in the regulation of SPL7 activity. Indeed, independent in vivo approaches indicated that the SPL7 N-terminal half is prone to self-dimerization. Accordingly, only SPL7 protein fragments encompassing at least the conserved signature RXSXKLX $\mathrm{PX}_{3} \mathrm{PX}_{2} \mathrm{LX}_{7} \mathrm{LX}_{7} \mathrm{EX}_{3} \mathrm{RXGCX}_{3} \mathrm{~T}$ denoted the IRPGC domain (albeit extended compared to previous reports $[16,17])$, were isolated in a Y2H screen using SPL7 as bait. Consequently, this signature could be considered to represent a dimerization domain. Homodimer formation involving this domain in the N-terminal half of SPL7 would also explain our observations on co-immunoprecipitated N-terminal SPL7 fragments, most likely generated through post-translational processing as discussed above. Similarly, only split YFP fragments fused as N-terminal tags to SPL7 were successful in BiFC assays. Furthermore, the reconstituted YFP fluorophore signal for $\mathrm{N}$-terminal fusions illuminated the nuclear surroundings and cytoplasmic filaments, in an ER-like distribution. However, these results seem to contradict observations on GFP-tagged SPL7-like proteins clearly located in the nucleus when overexpressed in heterologous systems (our results and $[14,26]$ ). Therefore, it is tempting to speculate that SPL7 preferentially enters the nucleus as a monomer. Exclusion of the dimer may be the result of the large size of the protein complex formed or of masking the NLS (Figure 8). In addition, rapid degradation or instability of SPL7 dimers cannot be ruled out as GFP:: SPL7 was not easily detectable outside the nucleus neither in fluorescence microscopy nor in biochemical approaches. Hence dimerization, likely promoted by increasing amounts of released SPL7 protein, may be part of a negative feedback mechanism to attenuate the homeostatic $\mathrm{Cu}$ deficiency response and eventually avoid spurious effects. Interestingly, given the conservation of the IRPGC signature not only in SPL7 orthologous proteins but also in closely related large SPLs in Arabidopsis [16], homodimerization, or even heterodimerization, may represent a more general regulatory feature of this type of SBP-domain TFs.

The participation of additional SPL7-interacting proteins in the SPL7 post-translational regulation mechanism cannot be excluded (Figure 8). Indeed, KIN17 associates with SPL7 in order to stimulate SPL7-targets and counteract the oxidative stress under $\mathrm{Cu}$ deprivation [26]. Nevertheless, we are not aware of mutants for other genes with a similar 
or even close impact on the global response to $\mathrm{Cu}$ deficiency as spl7 mutants have. Therefore we assume that the likely SPL7-interactome consists of largely functionally redundant components that probably contribute more to refine SPL7 function, rather than to its activation.

Importantly, SPL7 is expected to undergo a high turnover because different tagged full-sized SPL7-like proteins could not be clearly detected in stable transgenics, despite their functionality (our observations and $[9,10,14]$ ) and reasonable transgene transcript levels (Additional file 5: Figure S5). We also did not succeed to trace SPL7 in planta by observing different tissues at different time-points or using different tags, growth conditions or protein degradation inhibitors (data not shown). However, we demonstrated that expression of an N-terminal GFP-tagged SPL7 fragment including the SBP-domain but lacking the downstream IRPGC domain could be detected and resulted in a constitutive SPL7 function-related response irrespective of the $\mathrm{Cu}$ availability. A similar behaviour has been reported for other ER-attached proteins. A constitutive ethylene triple response is achieved by expressing putative C-terminal EIN2-cleaved fragments [45]. Similarly, the anac017-2 mutant, rendering a truncated version of ANAC017 without the TMD, induces its target ALTERNATIVE OXIDASE1 (AOX1), even in non- $\mathrm{H}_{2} \mathrm{O}_{2}$-treated plants [37]. Remarkably, the constitutive transcriptional activity of SPL7 targets in SPL7-SBP transgenic lines, even during non-physiological $\mathrm{Cu}$ excess, seem to contradict previous data showing that $\mathrm{Cu}$ ions negatively interfere the DNA-binding capacity of the SPL7 SBP-domain in vitro [14]. One should take into account that $\mathrm{Cu}$ ions cannot move freely within cells due to the efficient $\mathrm{Cu}$-chelating capacity of cells [49]. Moreover, a direct interaction between SPL7 and free $\mathrm{Cu}$ ions seems unlikely because $\mathrm{Cu}$ is mostly stored in organelles like the chloroplasts and mitochondria, whereas SPL7 distributes between endomembranes and nucleus. Nevertheless, a slight decrease in SPL7-targets could be even noticed in the SPL7-SBP plants during the transition from $\mathrm{Cu}$ deficiency to sufficiency. We, therefore, propose that the effect of $\mathrm{Cu}$ ions on the functionality of SPL7 is mediated by some interacting factor(s), such as specific metallochaperones (Figure 8). The respective interacting SPL7 domain(s) is then most likely C-terminal of the SBP-domain. An overlap with the IRPGC domain, as the main conserved signature within this region, cannot be excluded. Whether the dimerization through this domain constitutes a possible regulatory mechanism promoting SPL7 turnover needs to be further addressed.

\section{Conclusions}

Altogether, our data provide novel insights into the molecular mechanisms underlying the role of the SPL7 TF in orchestrating $\mathrm{Cu}$ homeostasis in plants. Additionally, the mechanism of action we have reported here for SPL7 may possibly be extrapolated to other large SBP-domain proteins because a conservation of particular structural features is suggested on the basis of amino acid sequence similarities.

\section{Methods}

\section{Plant growth and manipulation}

The wild-type line used in all the experiments corresponded to the Arabidopsis thaliana ecotype Columbia (Col-0). The spl7-2 mutant has been previously described by Bernal and colleagues [9]. Seeds were stratified at $4^{\circ} \mathrm{C}$ for 2 days prior to be sown. For in vitro culture, seeds were surface sterilized with sequential washes in ethanol $70 \%$ (5 min), bleach (5 min), water $(2 \times 2 \mathrm{~min})$, resuspended in agar $0.1 \%(\mathrm{w} / \mathrm{v})$ and sown on half-strength MS medium plates ( $1 / 2 \mathrm{MS}$; Sigma) supplemented with sucrose $1 \%(\mathrm{w} / \mathrm{v})$ and $\mathrm{CuSO}_{4}$ as indicated. $\mathrm{Cu}$-deficient growth conditions were achieved by adding the specific $\mathrm{Cu}$ chelator bathocuproine disulphonate (BCS; Sigma-Aldrich) to the medium. In all cases, long day conditions (16 h light, $20-23^{\circ} \mathrm{C} / 8 \mathrm{~h}$ darkness, $16^{\circ} \mathrm{C}$ ) were applied. To generate stable transgenic lines, constructs were introduced in wild-type and spl7-2 mutant plants using Agrobacterium tumefaciens GV3101 (pMP90RK) in the floral-dip method [50,51].

\section{Constructs}

cDNA fragments corresponding to the entire coding sequence or selected regions of SPL7 (AT5G18830.1) were amplified with specific oligonucleotides (Additional file 6: Table S1) and cloned into pDONR207 by means of the Gateway BP clonase II (Invitrogen). The generated entry clones were further recombined into the $p M D C 43$ or pMDC201 vectors with LR clonase II (Invitrogen) to add a GFP tag at either the amino- or carboxi-terminus, respectively [52]. Similarly, the pALLIGATOR2 vector was chosen to add a 3xHA tag to the N-terminus of full-sized SPL7 (HA::SPL7) [53]. For BiFC, full-sized SPL7 in pDONR207 was LR-recombined into both the pYFN43 and pYFC43 destiny vectors providing $\mathrm{N}$-terminal the two halves of YFP [54]. The ER marker fused to mCherry (ER-rk) used for subcellular co-localizations was described in Nelson and colleagues [28].

\section{Y2H screen}

The $\mathrm{Y} 2 \mathrm{H}$ assay was performed by Hybrigenics Services SAS using a fragment of SPL7 (aa residues 133 to 762) as bait to screen a random-primed cDNA prey library prepared from 1-week-old Arabidopsis seedlings.

\section{Subcellular localization and bimolecular fluorescence complementation assay on tobacco leaves}

To determine the subcellular localization of truncated SPL7 protein versions, Nicotiana benthamiana (tobacco) 
young leaves were co-infiltrated with diluted cultures of A. tumefaciens harbouring CaMV $35 \mathrm{~S}$ promoter-driven transgene constructs expressing fluorescent-tagged proteins of interest together with the $p 19$ plasmid [55] in infiltration buffer [D-glucose $0.5 \%(\mathrm{w} / \mathrm{v})$; MES $10 \mathrm{mM}$; $\mathrm{MgCl}_{2} 10 \mathrm{mM}$; acetosyringone $\left.0.1 \mathrm{mM}\right]$ at an $\mathrm{OD}_{600} 0.2$. Small pieces of leaves were excised 2-3 days after infiltration and examined in a confocal laser scanning microscope (Zeiss LSM700) using filters to select for the GFP and chlorophyll signal. For BiFC assays, the $p Y F N 43::$ SPL7 (nYFP::SPL7) and pYFC43::SPL7 (cYFP::SPL7) destiny vectors were individually or co-expressed in leaf epidermal tobacco cells as indicated above, and examined using widefield epifluorescence microscopy (Olympus BX61) and confocal laser scanning microscopy to asses the restoration of the YFP signal.

\section{Biochemical fractionation}

Biochemical fractionation was carried out according to Sáez and collaborators [56] with modifications: $3 \mathrm{~g}$ of transiently transformed tobacco leaves were homogenised in 3 volumes of extraction buffer [Tris- $\mathrm{HCl} 20 \mathrm{mM}$ pH 7.4; glycerol 25\% (v/v); KCl 20 mM; $\mathrm{MgCl}_{2} 2.5 \mathrm{mM}$; EDTA $2 \mathrm{mM}$; sucrose $250 \mathrm{mM}$; Pefabloc $1 \mathrm{mM}$; cOmplete Protease Inhibitor Cocktail (Roche) 1X], filtered through 2 Miracloth layers and centrifuged at $1000 \mathrm{~g}$ for $10 \mathrm{~min}$ at $4^{\circ} \mathrm{C}$ to pellet nuclei. Pellets were gently rinsed with $2 \mathrm{~mL}$ of Nuclei Wash Buffer [Tris-HCl $20 \mathrm{mM}$ pH 7.4; glycerol $25 \%$ (v/v); $\mathrm{MgCl}_{2} 2.5$ mM; Triton X-100 0.5\% (v/v)]. After centrifugation at $1000 \mathrm{~g}$ for $30 \mathrm{~s}$ pellets were resuspended in 5 volumes of Medium Salt Buffer [Tris- $\mathrm{HCl} 20 \mathrm{mM}$ $\mathrm{pH}$ 7.4; glycerol 5\%; $\mathrm{NaCl} 0.4 \mathrm{M}$; $\beta$-mercaptoethanol $1 \mathrm{mM}$; EDTA $1 \mathrm{mM}$; Pefabloc $0.5 \mathrm{mM}$; cOmplete Protease Inhibitor Cocktail $1 \mathrm{X}$ and stored frozen. Samples were thawed on ice, stirred for $15 \mathrm{~min}$ and centrifuged at $10000 \mathrm{~g}$ for $10 \mathrm{~min}$ to recover the supernatant, which was considered as the nuclear enriched fraction. To obtain the microsomal fraction, the initial supernatant was submitted to ultracentrifugation at $100000 \mathrm{~g}$ for $1 \mathrm{~h}$ in a SW-44 Ti rotor (Beckman) and the sediment was resuspended in extraction buffer. The remaining supernatant was used as the cytosolic fraction. All fractions were concentrated by means of Microcon Centrifugal Filter Devices (Merck Millipore) columns and equal amounts of proteins loaded on 10\% NuPAGE precasted gels (Life Technologies). Antibodies used for Western blot were: anti-GFP (1:1000; clones 7.1 and 13.1 Roche), anti-TPR7 (1:1000 [57]), anti-PEPC (1:15000; Rockland) and anti-H3 (1:10000; Abcam).

\section{Induction of ER stress in Arabidopsis seedlings}

ER stress was induced as described by $\mathrm{Li}$ and colleagues [32]. Thereto, wild-type and spl7-2 seedlings were grown on $1 / 2$ MS supplemented with sucrose $1 \%(\mathrm{w} / \mathrm{v})$ and $\mathrm{CuSO}_{4}$
$0.5 \mu \mathrm{M}$ for 5 days. Subsequently, they were cultured in liquid $1 / 2$ MS treated with tunicamycin $(5 \mu \mathrm{g} / \mathrm{mL})$ or DTT $(2 \mathrm{mM})$ during $3 \mathrm{~h}$ with gentle shaking. Material was harvested and used for gene expression assays by qPCR.

\section{Gene expression analysis by quantitative real-time PCR}

For gene expression assays, total RNA was prepared with the Spectrum Plant Total RNA Kit (Sigma-Aldrich) according to manufacturer's instructions. The RNA integrity was visualized in ethidium bromide-agarose gels. RNA samples were treated with DNase I recombinant RNase-free (Roche) and reverse transcribed to cDNA with the Superscript II Reverse Transcriptase (Invitrogen). qPCR analysis were carried out in an iQ5 Real-Time PCR Detection System (Bio-Rad) with EvaGreen (Biotium) and specific primers (see Additional file 7: Table S2) using an initial cycle at $95^{\circ} \mathrm{C}$ for $3 \mathrm{~min}$ and 40 cycles consisting in $95^{\circ} \mathrm{C}$ for $10 \mathrm{~s}, 58^{\circ} \mathrm{C}$ for $20 \mathrm{~s}$ and $72^{\circ} \mathrm{C}$ for $20 \mathrm{~s}$. ACT2 and EF1 were used to normalize gene expression values. Statistical analysis of at least three independent biological samples was performed using Excel (Microsoft Corporation). Student's $t$-test was used to determine statistically significant differences with a $\mathrm{p}<0.05$ or $\mathrm{p}<0.01$ as level of significance.

\section{Co-immunoprecipitation}

Total protein extracts from tobacco leaves transiently co-expressing HA::SPL7 and GFP::SPL7 were prepared by grinding frozen material in co-immunoprecipitation (CoIP) buffer [PIPES-KOH $10 \mathrm{mM} \mathrm{pH} \mathrm{7;} \mathrm{NaCl} 50 \mathrm{mM}$; EDTA $0.5 \mathrm{mM} \mathrm{pH} \mathrm{8.0;} \mathrm{Triton} \mathrm{X-100} \mathrm{0.5 \%} \mathrm{(v/v);} \mathrm{cOmplete}$ Protease Inhibitor Cocktail $1 \mathrm{X}]$ and crosslinked to a limited extent with formaldehyde $1 \%(\mathrm{v} / \mathrm{v})$. Samples were centrifuged at maximum speed at $4{ }^{\circ} \mathrm{C}$ for $5 \mathrm{~min}$ and 0.4 volumes $2 \mathrm{M}$ glycine were added to the supernatants in order to stop the crosslinking. Next, HA::SPL7 was pulled-down by incubating $1 \mathrm{~mL}$ of protein extract with $1.5 \mu \mathrm{g}$ of anti-HA high affinity antibody (3 F10 clone, Roche) on rotation at $4^{\circ} \mathrm{C}$ for $2 \mathrm{~h}$. Then, $50 \mu \mathrm{L}$ of equilibrated Protein G Mag Sepharose Xtra (GE Healthcare) magnetic beads were added to extracts and rotated overnight at $4^{\circ} \mathrm{C}$. Finally, beads were recovered, washed three times with $1 \mathrm{~mL}$ CoIP Buffer supplemented with $\mathrm{NaCl}$ $300 \mathrm{mM}$, Triton X-100 0.1\% (v/v) and cOmplete Protease Inhibitor Cocktail $1 \mathrm{X}$ and boiled at $95^{\circ} \mathrm{C}$ for $10 \mathrm{~min}$ with $50 \mu \mathrm{L}$ SDS-PAGE load buffer 4X. GFP::SPL7 coimmunopreciptitation was assessed by Western blot with anti-GFP-HRP (1:1000; Molecular Probes) and anti-HA-HRP (1:1000; Roche) antibodies.

\section{Availability of supporting data}

All the supporting data are included as additional files. 


\section{Additional files}

Additional file 1: Figure S1. Multiple sequence alignment of carboxy-termini and intermediate regions of SPL7 orthologous proteins. (a) and (b) Amino acid sequences from SPL7-like proteins were aligned using ClustalW within the MacVector software package with default parameters. Conserved signatures are indicated with red squares: TMD in (a) and IRPGC putative dimerization domain in (b). (c) Sequence logo IRPGC putative dimerization domain obtained with the Weblogo interface (http://weblogo.berkeley.edu/logo.cgi). Genbank accession numbers: Chlamydomonas reinhardtii AAY33924; Chlorella variabilis XP_005851140.1: Volvox carteri XP_002948544.1; Arabidopsis thaliana At5g18830.1; Arabidopsis Iyrata XP_002871844.1; Capsella rubella EOA22312.1; Thellungiella halophila BAJ34638.1; Sorghum bicolor XP_002439790.1; Oryza sativa NP_001055522.1; Amborella trichopoda ERN18478; Vitis vinifera XP_002277039.1; Physcomitrella patens ABM67299.1; Hordeum vulgare BAJ96319.1; Ricinus communis XP_002516839.1; Glycine max XP_003547221.1; Picea sitchensis ABR17971.1; Solanum lycopersicum XP_004229492.1; Theobroma cacao EOY06351.1; Zea mays AFW81967.1.

Additional file 2: Figure S2. Nuclear localization of the N-terminal GFP tagged SPL7. Epidermal tobacco leaves were co-infiltrated with GFP::SPL7 and the nuclear marker pSAT6-mCherry-VirD2NLS [58] and examined using confocal microscopy. A representative image of the respective GFP and $\mathrm{mCherry}$ signals are shown together with the corresponding bright field and merged images. Scale bar, $10 \mu \mathrm{m}$.

Additional file 3: Figure S3. A yeast two-hybrid assay uncovers SPL7 homodimerization. Using a SPL7 bait including aa residues 133 to 762 in a $\mathrm{Y} 2 \mathrm{H}$ assay retrieved 8 independent preys corresponding to SPL7 derived polypeptides. The cartoon depicts their alignment relative to the bait and the full-size SPL7 protein with the conserved domains (SBP; IRPGC; TMD) indicated with squares. The common region shared by all preys (shaded green) and the presence of the IRPGC domain (shaded red) are highlighted. The position of the $\mathrm{N}$ - and C-termina amino acid residues relative to the full-size SPL7 protein is provided.

Additional file 4: Figure S4. Complementation of the sp/7-2 mutant phenotype by two different SPL7 protein derived polypeptides. (a) Seedlings of the wild-type (WT), sp/7-2 mutant and transformed sp/7-2 lines expressing the indicated GFP-tagged SPL7 protein-derived polypeptides (GFP-SPL7; GFP-SBP) grown on vertically placed agar plates containing $1 / 2$ MS supplemented with sucrose $1 \%$ and BCS $50 \mu \mathrm{M}(-\mathrm{Cu})$ or $\mathrm{CuSO}_{4} 5 \mu \mathrm{M}(+\mathrm{Cu})$ for 5 days before imaging (upper panel). (b) Root length measurement of plants in (a). Bars represent the mean with error bars corresponding to the standard deviation $(n>9)$. Asterisk indicates statistically significant difference to comparably grown wild type according to Student's $t$-test $(p<0.01)$. (c) Complementation of sp/7-2 phenotypes in adult plants. Phenotypes of 1-month-old spl7-2 mutant plants complemented with the respective SPL7 protein derived polypeptides in comparison to wild-type and sp/7-2 single mutant plants grown on standard soil.

Additional file 5: Figure S5. Detection of endogenous and transgene derived SPL7 transcripts in GFP::SPL7 transgenic lines. Total RNA was isolated from 7-day-old seedlings grown under Cu deficiency (BCS $50 \mu \mathrm{M}$ ) and Cu mild excess (Cu $5 \mu \mathrm{M}$ ) and corresponding to the $\mathrm{WT}$, spl7-2 mutant and two transgenic lines expressing GFP-SPL7 against an spl7-2 mutant background. Relative transcript levels of endogenous SPL7 (with an SPL7 specific primer pair) and transgenic GFP-SPL7 (with a GFP specific primer pair) were determined by $\mathrm{QPCR}$. Error bars represent the standard deviation of 3 technical replicates.

Additional file 6: Table S1. Oligonucleotides used for cloning. The name, sequence $\left(5^{\prime}-3^{\prime}\right)$ and target for each oligonucleotide is provided.

Additional file 7: Table S2. Oligonucleotides used for quantitative real-time PCR. The name and sequence $\left(5^{\prime}-3^{\prime}\right)$ for each combination of oligonucleotides are provided.

\section{Competing interests}

The authors declare that they have no competing interests.

\section{Authors' contributions}

AG-M performed the experimental procedures under SX and PH supervision. AG-M, SX and PH participated in the design of experiments, work progress discussions and all together contributed to the elaboration of the manuscript and figures. All authors read and approved the manuscript.

\section{Acknowledgements}

We thank Elmon Schmelzer (CeMic-MPIPZ, Cologne) for his advice and instructions on confocal microscopy, and Arne Grande, Susanne Höhmann and Rita Berndtgen (MPIPZ, Cologne) for their excellent technical support. Antibodies against $\mathrm{H} 3$ and PEPC were kindly provided by George Coupland's and Jane Parker's groups (MPIPZ, Cologne), respectively. François Parcy (CEACNRS; Grenoble) and Alejandro Ferrando (IBMCP-CSIC; València) are acknowledged for kindly providing the pALLIGATOR2 and pYFN43 and pYFC43 vectors, respectively.

\section{Author details}

'Department of Comparative Development and Genetics, Max Planck Institute for Plant Breeding Research, Cologne 50829, Germany. ${ }^{2}$ Current address: Lehrstuhl für Systembiologie der Pflanzen, Technische Universität München, Emil-Ramann-Strasse 4, Freising 85354, Germany. ${ }^{3}$ Current address: Department of Developmental Genetics, Centre for Plant Molecular Biology, Universität Tübingen, Auf der Morgenstelle 32, Tübingen 72076, Germany.

Received: 14 April 2014 Accepted: 18 August 2014

Published: 30 August 2014

\section{References}

1. Wang JW, Schwab R, Czech B, Mica E, Weigel D: Dual effects of miR156-targeted SPL genes and CYP78A5/KLUH on plastochron length and organ size in Arabidopsis thaliana. Plant Cell 2008, 20(5):1231-1243.

2. Stone JM, Liang X, Nekl ER, Stiers JJ: Arabidopsis AtSPL14, a plant-specific SBP-domain transcription factor, participates in plant development and sensitivity to fumonisin B1. Plant J 2005, 41(5):744-754.

3. Shikata M, Koyama T, Mitsuda N, Ohme-Takagi M: Arabidopsis SBP-box genes SPL10, SPL11 and SPL2 control morphological change in association with shoot maturation in the reproductive phase. Plant Cell Physiol 2009, 50(12):2133-2145.

4. Bergonzi S, Albani MC, Ver Loren van Themaat E, Nordstrom KJ, Wang R, Schneeberger K, Moerland PD, Coupland G: Mechanisms of agedependent response to winter temperature in perennial flowering of Arabis alpina. Science 2013, 340(6136):1094-1097.

5. Xing S, Salinas M, Garcia-Molina A, Höhmann S, Berndtgen R, Huijser P: SPL8 and miR156-targeted SPL genes redundantly regulate Arabidopsis gynoecium differential patterning. Plant J 2013, 75(4):566-577.

6. Xing S, Salinas M, Höhmann S, Berndtgen R, Huijser P: miR156-targeted and nontargeted SBP-box transcription factors act in concert to secure male fertility in Arabidopsis. Plant Cell 2010, 22(12):3935-3950.

7. Zhang Y, Schwarz S, Saedler H, Huijser P: SPL8, a local regulator in a subset of gibberellin-mediated developmental processes in Arabidopsis. Plant Mol Biol 2007, 63(3):429-439.

8. Padmanabhan MS, Ma S, Burch-Smith TM, Czymmek K, Huijser P, Dinesh-Kumar SP: Novel positive regulatory role for the SPL6 transcription factor in the N TIR-NB-LRR receptor-mediated plant innate immunity. PLOS Pathog 2013, 9(3):e1003235.

9. Bernal M, Casero D, Singh V, Wilson GT, Grande A, Yang H, Dodani SC, Pellegrini M, Huijser P, Connolly EL, Merchant SS, Krämer U: Transcriptome sequencing identifies SPL7-regulated copper acquisition genes FRO4/FRO5 and the copper dependence of iron homeostasis in Arabidopsis. Plant Cell 2012, 24(2):738-761.

10. Yamasaki H, Hayashi M, Fukazawa M, Kobayashi Y, Shikanai T: SQUAMOSA Promoter Binding Protein-Like7 Is a Central Regulator for Copper Homeostasis in Arabidopsis. Plant Cell 2009, 21(1):347-361.

11. Birkenbihl RP, Jach G, Saedler $H$, Huijser P: Functional dissection of the plant-specific SBP-domain: overlap of the DNA-binding and nuclear localization domains. J Mol Biol 2005, 352(3):585-596.

12. Klein J, Saedler $H$, Huijser P: A new family of DNA binding proteins includes putative transcriptional regulators of the Antirrhinum majus floral meristem identity gene SQUAMOSA. Mol Gen Genet 1996, 250(1):7-16. 
13. Yamasaki K, Kigawa T, Inoue M, Tateno M, Yamasaki T, Yabuki T, Aoki M, Seki E, Matsuda T, Nunokawa E, Ishizuka Y, Terada T, Shirouzu M, Osanai T, Tanaka A, Seki M, Shinozaki K, Yokoyama S: A novel zinc-binding motif revealed by solution structures of DNA-binding domains of Arabidopsis SBP-family transcription factors. J Mol Biol 2004, 337(1):49-63.

14. Sommer F, Kropat J, Malasarn D, Grossoehme NE, Chen X, Giedroc DP, Merchant SS: The CRR1 nutritional copper sensor in Chlamydomonas contains two distinct metal-responsive domains. Plant Cell 2010, 22(12):4098-4113.

15. Yamasaki K, Kigawa $T$, Inoue $M$, Yamasaki T, Yabuki T, Aoki M, Seki E, Matsuda T, Tomo Y, Terada T, Shirouzu M, Tanaka A, Seki M, Shinozaki K, Yokoyama S: An Arabidopsis SBP-domain fragment with a disrupted C-terminal zinc-binding site retains its tertiary structure. FEBS Lett 2006, 580(8):2109-2116.

16. Riese M, Höhmann S, Saedler H, Münster T, Huijser P: Comparative analysis of the SBP-box gene families in P. patens and seed plants. Gene 2007, 401(1-2):28-37.

17. Kropat J, Tottey S, Birkenbihl RP, Depege N, Huijser P, Merchant S: A regulator of nutritional copper signaling in Chlamydomonas is an SBP domain protein that recognizes the GTAC core of copper response element. Proc Natl Acad Sci U S A 2005, 102(51):18730-18735.

18. Rhoades MW, Reinhart BJ, Lim LP, Burge CB, Bartel B, Bartel DP: Prediction of plant microrna targets. Cell 2002, 110(4):513-520.

19. Schwab R, Palatnik JF, Riester M, Schommer C, Schmid M, Weigel D: Specific effects of micrornas on the plant transcriptome. Dev Cell 2005 , 8(4):517-527.

20. Burkhead JL, Reynolds KA, Abdel-Ghany SE, Cohu CM, Pilon M: Copper homeostasis. New Phytol 2009, 182(4):799-816

21. Puig S, Andres-Colas N, Garcia-Molina A, Peñarrubia L: Copper and iron homeostasis in Arabidopsis: responses to metal deficiencies, interactions and biotechnological applications. Plant Cell Environ 2007, 30(3):271-290

22. Kuper J, Llamas A, Hecht HJ, Mendel RR, Schwarz G: Structure of the molybdopterin-bound $\mathrm{Cn} \times 1 \mathrm{G}$ domain links molybdenum and copper metabolism. Nature 2004, 430(7001):803-806.

23. Rodriguez FI, Esch JJ, Hall AE, Binder BM, Schaller GE, Bleecker AB: A copper cofactor for the ethylene receptor ETR1 from Arabidopsis. Science 1999, 283(5404):996-998.

24. Wu Y, Zhang D, Chu JY, Boyle P, Wang Y, Brindle ID, De Luca V, Despres C: The Arabidopsis NPR1 protein is a receptor for the plant defense hormone salicylic acid. Cell Rep 2012, 1(6):639-647.

25. Halliwell B, Gutteridge JM: Lipid peroxidation, oxygen radicals, cell damage, and antioxidant therapy. Lancet 1984, 1(8391):1396-1397.

26. Garcia-Molina A, Xing S, Huijser P: A conserved KIN17 curved DNA-binding domain protein assembles with SQUAMOSA PROMOTER-BINDING PROTEIN-LIKE7 to adapt arabidopsis growth and development to limiting copper availability. Plant Physiol 2014, 164(2):828-840.

27. Krogh A, Larsson B, von Heijne G, Sonnhammer EL: Predicting transmembrane protein topology with a hidden Markov model: application to complete genomes. J Mol Biol 2001, 305(3):567-580.

28. Nelson BK, Cai X, Nebenfuhr A: A multicolored set of in vivo organelle markers for co-localization studies in Arabidopsis and other plants. Plant J 2007, 51(6):1126-1136

29. Wahyu Indra Duwi F, Lee SY, Lee KO: The unfolded protein response in plants: a fundamental adaptive cellular response to internal and external stresses. J Proteome 2013, 93(0):356-368.

30. Howell SH: Endoplasmic reticulum stress responses in plants. Annu Rev Plant Biol 2013, 64:477-499.

31. Andrés-Colás N, Perea-García A, Mayo de Andrés S, Garcia-Molina A, Dorcey E, Rodríguez-Navarro S, Pérez-Amador MA, Puig S, Peñarrubia L: Comparison of global responses to mild deficiency and excess copper levels in Arabidopsis seedlings. Metallomics 2013, 5(9):1234-46.

32. Li B, Yi P, Zhang B, Xu C, Liu Q, Pi Z, Xu X, Chevet E, Liu J: Differences in endoplasmic reticulum stress signalling kinetics determine cell survival outcome through activation of MKP-1. Cell Signal 2011, 23(1):35-45.

33. Seo PJ, Kim MJ, Song JS, Kim YS, Kim HJ, Park CM: Proteolytic processing of an Arabidopsis membrane-bound NAC transcription factor is triggered by cold-induced changes in membrane fluidity. Biochem J 2010, 427(3):359-367.

34. Deng Y, Humbert S, Liu JX, Srivastava R, Rothstein SJ, Howell SH: Heat induces the splicing by IRE1 of a mRNA encoding a transcription factor involved in the unfolded protein response in Arabidopsis. Proc Natl Acad Sci U S A 2011, 108(17):7247-7252.

35. Nagashima Y, Mishiba K-i, Suzuki E, Shimada Y, Iwata Y, Koizumi N: Arabidopsis IRE1 catalyses unconventional splicing of bZIP60 mRNA to produce the active transcription factor. Sci Rep 2011, 1:29.

36. Liu JX, Srivastava R, Che P, Howell SH: An endoplasmic reticulum stress response in Arabidopsis is mediated by proteolytic processing and nuclear relocation of a membrane-associated transcription factor, bZIP28. Plant Cell 2007, 19(12):4111-4119.

37. Ng S, Ivanova A, Duncan O, Law SR, Van Aken O, De Clercq I, Wang Y, Carrie C, Xu L, Kmiec B, Walker H, Van Breusegem F, Whelan J, Giraud E: A Membrane-Bound NAC Transcription Factor, ANAC017, Mediates Mitochondrial Retrograde Signaling in Arabidopsis. Plant Cell 2013, 25(9):3450-3471.

38. Hoppe T, Rape M, Jentsch S: Membrane-bound transcription factors: regulated release by RIP or RUP. Curr Opin Cell Biol 2001, 13(3):344-348.

39. Andreasson C, Heessen S, Ljungdahl PO: Regulation of transcription factor latency by receptor-activated proteolysis. Genes Dev 2006, 20(12):1563-1568

40. Pufahl RA, Singer CP, Peariso KL, Lin SJ, Schmidt PJ, Fahrni CJ, Culotta VC Penner-Hahn JE, O'Halloran TV: Metal ion chaperone function of the soluble Cu(I) receptor Atx1. Science 1997, 278(5339):853-856.

41. Puig S, Mira H, Dorcey E, Sancenon V, Andres-Colas N, Garcia-Molina A Burkhead JL, Gogolin KA, Abdel-Ghany SE, Thiele DJ, Ecker JR, Pilon M, Peñarrubia L: Higher plants possess two different types of ATX1-like copper chaperones. Biochem Biophys Res Commun 2007, 354(2):385-390.

42. Chen YF, Randlett MD, Findell JL, Schaller GE: Localization of the ethylene receptor ETR1 to the endoplasmic reticulum of Arabidopsis. J Biol Chem 2002, 277(22):19861-19866.

43. Hirayama T, Kieber JJ, Hirayama N, Kogan M, Guzman P, Nourizadeh S, Alonso JM, Dailey WP, Dancis A, Ecker JR: RESPONSIVE-TO-ANTAGONIST1, a Menkes/Wilson disease-related copper transporter, is required for ethylene signaling in Arabidopsis. Cell 1999, 97(3):383-393.

44. Pilon M, Abdel-Ghany SE, Cohu CM, Gogolin KA, Ye H: Copper cofactor delivery in plant cells. Curr Opin Plant Biol 2006, 9(3):256-263.

45. Qiao H, Shen Z, Huang SS, Schmitz RJ, Urich MA, Briggs SP, Ecker JR: Processing and subcellular trafficking of ER-tethered EIN2 control response to ethylene gas. Science 2012, 338(6105):390-393.

46. Gilchrist DG: Mycotoxins reveal connections between plants and animals in apoptosis and ceramide signaling. Cell Death Differ 1997, 4(8):689-698.

47. Senkal CE, Ponnusamy S, Bielawski J, Hannun YA, Ogretmen B: Antiapoptotic roles of ceramide-synthase-6-generated C16-ceramide via selective regulation of the ATF6/CHOP arm of ER-stress-response pathways. FASEB J 2010, 24(1):296-308.

48. Senkal CE, Ponnusamy S, Manevich Y, Meyers-Needham M, Saddoughi SA, Mukhopadyay A, Dent P, Bielawski J, Ogretmen B: Alteration of ceramide synthase 6/C16-ceramide induces activating transcription factor 6-mediated endoplasmic reticulum (ER) stress and apoptosis via perturbation of cellular $\mathrm{Ca} 2+$ and ER/Golgi membrane network. J Biol Chem 2011, 286(49):42446-42458.

49. Rae TD, Schmidt PJ, Pufahl RA, Culotta VC, O'Halloran TV: Undetectable intracellular free copper: the requirement of a copper chaperone for superoxide dismutase. Science 1999, 284(5415):805-808.

50. Clough SJ, Bent AF: Floral dip: a simplified method for Agrobacterium-mediated transformation of Arabidopsis thaliana. Plant J 1998, 16(6):735-743.

51. Koncz C, Schell J: The promoter of TL-DNA gene 5 controls the tissue-specific expression of chimaeric genes carried by a novel type of Agrobacterium binary vector. MGG 1986, 204(3):383-396.

52. Curtis MD, Grossniklaus U: A gateway cloning vector set for high-throughput functional analysis of genes in planta. Plant Physiol 2003, 133(2):462-469.

53. Bensmihen S, To A, Lambert G, Kroj T, Giraudat J, Parcy F: Analysis of an activated $\mathrm{ABI} 5$ allele using a new selection method for transgenic Arabidopsis seeds. FEBS Lett 2004, 561(1-3):127-131

54. Belda-Palazon B, Ruiz L, Marti E, Tarraga S, Tiburcio AF, Culianez F, Farras R, Carrasco $P$, Ferrando A: Aminopropyltransferases involved in polyamine biosynthesis localize preferentially in the nucleus of plant cells. PLoS One 2012, 7(10):e46907

55. Voinnet O, Rivas S, Mestre P, Baulcombe D: An enhanced transient expression system in plants based on suppression of gene silencing by the p19 protein of tomato bushy stunt virus. Plant J 2003, 33(5):949-956 
56. Saez A, Rodrigues A, Santiago J, Rubio S, Rodriguez PL: HAB1-SWI3B interaction reveals a link between abscisic acid signaling and putative SWI/SNF chromatin-remodeling complexes in Arabidopsis. Plant Cell 2008, 20(11):2972-2988.

57. Schweiger R, Muller NC, Schmitt MJ, Soll J, Schwenkert S: AtTPR7 is a chaperone-docking protein of the Sec translocon in Arabidopsis. J Cell Sci 2012, 125(Pt 21):5196-5207.

58. Lee LY, Fang MJ, Kuang LY, Gelvin SB: Vectors for multi-color bimolecular fluorescence complementation to investigate protein-protein interactions in living plant cells. Plant Methods 2008, 4:24.

doi:10.1186/s12870-014-0231-5

Cite this article as: Garcia-Molina et al.: Functional characterisation of Arabidopsis SPL7 conserved protein domains suggests novel regulatory mechanisms in the $\mathrm{Cu}$ deficiency response. BMC Plant Biology 2014 14:231.

\section{Submit your next manuscript to BioMed Central and take full advantage of:}

- Convenient online submission

- Thorough peer review

- No space constraints or color figure charges

- Immediate publication on acceptance

- Inclusion in PubMed, CAS, Scopus and Google Scholar

- Research which is freely available for redistribution 